\title{
EDITORIAL
}

\section{NEOCONSERVADORISMO, EDUCAÇÃO E PRIVAÇÃO DE DIREITOS}

contecimentos recentes indicam que estamos diante de um inequívo-
co recrudescimento do conservadorismo, tanto em termos nacionais
quanto internacionais. A aprovação do Brexit na Inglaterra, a eleição de Donald Trump nos Estados Unidos, bem como as eleiçóes na França, na Alemanha, na Áustria e, ainda mais recentemente, na Tchecoslováquia, confirmam essa tendência. $\mathrm{O}$ mesmo ocorre no Brasil e em diversos países da América Latina, seja no âmbito da formulação de políticas, seja na esfera das relaçóes sociais e culturais. Entre nós, o projeto da reforma previdenciária, da Escola sem Partido ou a tentativa de silenciamento da filósofa americana Judith Butler são momentos expressivos dessa recente onda conservadora.

Os estratégicos ataques às conquistas sociais e aos direitos humanos compóem, na atual conjuntura, um quadro de retrocesso político de dimensóes inigualáveis, se comparado ao período recente da sociedade brasileira que parecia encaminhar-se à superação de períodos históricos opressores, forjados por séculos de escravidão, de patrimonialismo e de relaçóes sociais capitalistas altamente excludentes e autoritárias. Agora, impóe-se um movimento de liberalização das relaçóes de e no mercado, principalmente as que envolvem a contratação da força de trabalho e de ampliação da regulação sobre a vida privada. É essa conjuntura atual que a literatura crítica tem, de modo recorrente, designado como onda conservadora.

Para a ciência política, a expressão conservador pode ser entendida como substantivo, o que implica a existência de um conceito, e como adjetivo, qualificando simplesmente atitudes práticas ou ideias. Importa entender o conservadorismo do ponto de vista conceitual, sem, no entanto, desprezar sua dimensão adjetiva (SILVA, 2010, p. 53). No Dicionário de política, de Bobbio, Matteucci e Pasquino (2000), o termo conservadorismo designa "ideias e atitudes que visam à manutenção do sistema político existente e dos seus modos de funcionamento, apresentando-se como contraponto das forças inovadoras" (BONAZZI, 2000, p. 243).

A interpretação do conservadorismo realiza-se por meio da apreensão analítica do seu conteúdo eminentemente histórico, levando em conta o seu de-

DOI: 10.1590/ES0101-73302017v38n141ED 
senvolvimento alternativo em relaçáo ao progressismo. Ambos os conceitos conservadorismo e progressismo - "são inseparáveis dos processos históricos de secularização e laicização do pensamento político e social europeu” (SILVA, 2010, p. 53), pelo qual se produz a distinção entre a visão tradicional da origem divina do ser e a emergência do indivíduo autônomo capaz de, por intermédio da racionalidade, definir seu próprio destino (BONAZZI, 2000, p. 24).

De acordo com os autores, nem as concepçóes conservadoras nem as progressistas são homogêneas, tendo produzido ao longo da história diferentes formas de pensamento político. Edmund Burke (1729-1797), em sua investida contra o Iluminismo, pode ser considerado como o principal representante do conservadorismo no século XVIII. No século XIX, foram conservadores o positivismo de Augusto Comte (1798-1857), o evolucionismo liberal de Herbert Spencer (1820-1903) e o nacionalismo autoritário de inspiração romântica ou imperialista, não em termos de juízo de valor, mas de contraposição à dinâmica do progressismo representado por movimentos como o liberalismo, o socialismo e o nacionalismo (BONAZZI, 2000, p. 245).

No entanto, como adverte Bonazzi (2000, p. 246), no século XX, a entrada das massas na cena política passou a constituir o principal pesadelo do conservadorismo, modificando a antítese conservadorismo-progressismo. Veja-se, por exemplo, o pensamento de Ortega y Gasset (apud BONAZZI, 2000, p. 245-246), que definia as massas como incapazes de raciocínio e de uma ação independente, ou os apelos conservadores ao individualismo (possessivo), "com sua mais alta expressão no neoconservadorismo estadunidense, de inspiração burkeana”.

As análises de Losurdo (2006, p. 99) caminham na mesma direção. Segundo ele, essa visão permanece nos dias atuais por meio dos escritos de autores como Hayek (1899-1992), protagonista importante da "nova direita", ao defender que uma sociedade liberal poderia muito bem se negar a conceder o sufrágio às massas. O direito do voto é negado, também, "às pessoas muito jovens". Tal liberalismo não propóe privar o povo apenas dos direitos políticos, mas o exclui ainda dos direitos civis.

Haveria, segundo o autor, uma "gigantesca tentativa de purificar a sociedade 'liberal-democrática' dos elementos (ou do maior número possível de elementos) de democracia, daquilo que inseriram as lutas prolongadas do movimento democrático-socialista" (LOSURDO, 2006, p. 109). Nesse sentido, Losurdo (2006) retoma análise de Dahrendorf (1929-2009), que identifica no conservadorismo atual (ou neoconservadorismo) "a tentativa de reverter a 'ideia de direitos civis e sociais', de privar a ideia de direito daquela 'substância social' que é o resultado da resposta que a sociedade aberta apresenta aos desafios da luta de classes" (LOSURDO, 2006, p. 109).

Para Losurdo (2006, p. 109-110), apesar de suas diferenças, o neoconservadorismo e o neoliberalismo acabam encontrando-se com a velha e a nova 
direita "na liquidação, não apenas do movimento socialista, mas da herança da Revoluçáo Francesa e da ideia de igualdade, do Estado Providência". O autor vai ainda mais longe ao afirmar que a destruiçáo da herança do movimento democrático-socialista "não pode deixar de colidir com o conceito de homem e de direitos do homem como tal" (LOSURDO, 2006, p. 110), com seus direitos universais.

Nesse processo, na perspectiva de interpretar o movimento conservador atual, é importante retomar uma vez mais as formulaçóes de Bonazzi (2000, p. 245-247). Conforme esse autor, o que o conservadorismo pretendia obter servindo-se do poder político - "condição indispensável à convivência social que é necessário controlar, mas não destruir" —, passou agora a ser solicitado "à objetividade das normas de organizaçáo". Estaríamos, assim, assistindo ao ocaso da oposiçẫo conservadorismo $x$ progressismo nos moldes conhecidos e "à sua substituição por uma forma política autojustificativa, dominada pela coação objetiva das regras do desenvolvimento econômico-social" (BONAZZI, 2000, p. 245-247).

As consideraçóes analíticas mais recentes de Dardot e Laval (2016, p. 8), apontam convergências com as apresentadas anteriormente. O neoliberalismo, segundo eles, está fazendo-nos entrar na "era pós-democrática". Em seu antidemocratismo, "o direito privado deveria ser isentado de qualquer deliberação e qualquer controle, mesmo sob a forma do sufrágio universal" (DARDOT; LAVAL, 2016, p. 8). O neoliberalismo atua em escala mundial, sendo "instaurado por forças e poderes que se apoiam uns nos outros em nível nacional e internacional" (DARDOT; LAVAL, 2016, p. 8). O acúmulo de problemas não resolvidos, de tensóes, o aumento das desigualdades, dos desequilíbrios especulativos "preparam dias cada vez mais difíceis para as populaçóes" dos diferentes países (DARDOT; LAVAL, 2016, p. 8). Para esses autores, o neoliberalismo transformou profundamente o capitalismo, modificando as sociedades. A eficácia política na luta por sua superação exige análise precisa da situação, e compreender politicamente o neoliberalismo pressupóe que se entenda o projeto que ele representa desde os anos 1930.

Como resposta à grande crise econômica, política e doutrinária do período, o neoliberalismo introduziu claro rompimento em relação à versão liberal do século XIX, desenvolvendo uma revisão assumida do velho laisse$z$-faire, considerado insuficiente para a condução nos negócios do governo. Combater o socialismo e todas as versóes de "totalitarismo" exigia um trabalho de refundação das bases intelectuais do liberalismo. A revisão "do naturalismo liberal" transmitido ao longo do século XIX leva ao surgimento de duas concepçốes distintas: "o novo liberalismo", cuja expressão tardia e mais elaborada no plano da teoria econômica foi a de Keynes (1883-1946), e o "neoliberalismo", que surgiu mais tarde e se propóe como alternativa "aos tipos de intervenção 
econômica do reformismo social pregados pelo 'novo liberalismo'" (DARDOT; LAVAL, 2016, p. 69).

A refundação "neoliberal" ocorreu a partir do Colóquio Walter Lippmann, em 1938, manifestando-se em duas correntes: a corrente do ordoliberalismo alemão, representada, sobretudo, por Walter Eucken (1891-1950) e Wilhelm Röpke (1899-1966), e a corrente austro-americana, representada por Ludwig von Mises (1881-1973) e Friedrich A. Hayek (DARDOT; LAVAL, 2016, p. 33). O neoliberalismo não seria, portanto, o herdeiro natural do primeiro liberalismo. Ele não retoma a questão dos limites ao governo político, ao mercado, aos direitos ou ao cálculo da utilidade, mas "sobre como fazer do mercado tanto o princípio do governo dos homens como o do governo de si" (DARDOT; LAVAL, 2016, p. 33). Isto é, consiste precisamente no "desenvolvimento da lógica do mercado como lógica normativa generalizada, desde o Estado até o mais íntimo da subjetividade" (DARDOT; LAVAL, 2016, p. 33).

Dardot e Laval (2016) insistem, à maneira de Foucault (1926-1984), que o neoliberalismo não só destrói regras, instituiçôes e direitos. Ele também "produz certos tipos de relaçóes sociais, certas maneiras de viver, certas subjetividades" (DARDOT; LAVAL, 2016, p. 16, grifo do original). Em resumo, com o neoliberalismo está em jogo nada mais do que "a forma de nossa existência", "a forma como somos levados a nos comportar, a nos relacionar com os outros e com nós mesmos" (DARDOT; LAVAL, 2016, p. 33). Essa "norma de vida", presente em todas as sociedades ocidentais capitalistas,

impóe a cada um de nós que vivamos num universo de competição generalizada, intima os assalariados e as populaçóes a entrar em luta econômica uns contra os outros, ordena as relaçôes sociais segundo o modelo do mercado, obriga a justificar desigualdades cada vez mais profundas, muda até o indivíduo, que é instado a conceber a si mesmo e a comportar-se como uma empresa. Há quase um terço de século, essa norma de vida rege as políticas públicas, comanda as relaçóes econômicas mundiais, transforma a sociedade, remodela subjetividade (DARDOT; LAVAL, 2016, p. 16).

Em sua dimensão global, a "nova razão do mundo" se expressa: politicamente, na conquista de governos; economicamente, no crescimento rápido do capitalismo financeiro globalizado; socialmente, na individualização das relaçóes sociais e no aumento das desigualdades extremas; e subjetivamente, na conformação de um novo sujeito e no desenvolvimento de novas patologias clínicas. Como esclarecem os autores, essa "razão-mundo" é global nos dois sentidos que o termo pode ter: é global por sua tendência de ser "mundial", de se estender mundialmente, e é global por não se restringir às relaçóes econômicas, porém por tender a abranger, com seu "poder de integraçấo", a "todas as dimensôes da vida humana” (DARDOT; LAVAL, 2016, p. 16). 
Em sua obra $A$ escola não é uma empresa, publicada em 2004, Laval defende que uma das principais transformaçóes que afetaram o campo educativo nos últimos decênios, e também outros campos sociais, foi "a monopolização progressiva pela ideologia neoliberal do discurso e da dinâmica reformadora" (LAVAL, 2004, p. X). Inicialmente, enfatiza o que sabemos: o modelo escolar neoliberal considera a educação " como um bem essencialmente privado e cujo valor é, antes de tudo, econômico" (LAVAL, 2004, p. XII). Nessa perspectiva, "não é a sociedade que garante a todos os seus membros um direito à cultura, são os indivíduos que devem capitalizar recursos privados cujo rendimento futuro será garantido pela sociedade" (LAVAL, 2004, p. XII). Sobretudo, a despesa educativa deve ser "'rentável' para as empresas utilizadoras do 'capital humano"” (LAVAL, 2004, p. XII).

Nessa medida, as reformas liberais da educação "são duplamente guiadas pelo papel crescente do saber na atividade econômica e pelas restriçóes impostas pela competiçấo sistemática das economias" (LAVAL, 2004, XIII). Em escala mundial, essas reformas - que passam a pressionar para a descentralização, a padronização de métodos e conteúdos, o "novo" gerenciamento das escolas e a "profissionalização dos professores" —, são fundamentalmente, na expressão de Martin Carnoy, competitivity-centred (apud LAVAL, 2004, XIII). Em outras palavras, na "nova ordem educativa" em gestação, "o sistema educativo está a serviço da competitividade econômica, está estruturado como um mercado e deve ser gerido ao modo das empresas" (LAVAL, 2004, p. 20).

$\mathrm{Na}$ avaliação de Laval (2004), com a imposição do modelo neoliberal, a questão escolar não é mais o que se denomina de "problema social", mas "tende a se tornar uma questão de civilização". Nesse ponto, faz observaçóes relevantes em seu diagnóstico educacional. Considera, em primeiro lugar, que a mutação da escola não é uma espécie de complô, mas processo muito difuso e diverso, apresentando diferentes configuraçóes nacionais e internacionais que os organismos internacionais (Organização Mundial do Comércio — OMC, Organização para a Cooperação e Desenvolvimento Econômico - OCDE, Banco Mundial, Fundo Monetário Internacional - FMI, Comissão Europeia), com seu poder financeiro, tendem a ter por meio de suas "avaliaçóes" e "comparaçóes" "um papel de centralização política e de normalização simbólica considerável" na "recomposição de um modelo de escola", na criação de um modelo educacional homogêneo de caráter mundializado (LAVAL, 2004, p. XIV).

Em segundo lugar, no seu entender, "o acesso universal à cultura escrita, letrada, científica e técnica pela educação pública e instituiçôes culturais se torna uma utopia irrealizável", na medida em que contraria a "preeminência da acumulaçáo do capital sobre qualquer outro fim consciente da sociedade" (LAVAL, 2004, p. XVI). Realizar esse direito universal à cultura supóe financiamento público ampliado - sob a forma de imposto ou de cotizaçôes sociais — que con- 
traria "as políticas liberais de baixa das contribuiçôes obrigatórias, baixa que visa a aumentar a despesa privada e a estender a esfera mercantil em detrimento da esfera pública" (LAVAL, 2004, p. XVI). Nessas condiçôes, o direito à educação não pode se concretizar enquanto demanda solvível, que será destinada cada vez mais e "de modo muito desigual" à educação privada. Soma-se a isso o aprisionamento do desejo subjetivo dos jovens promovido pela "'socialização-atomização' mercantil das alegrias intelectuais", dificultando a sua apreensão da cultura na escola (LAVAL, 2004, p. XVI).

O quadro diagnosticado, embora grave, não é sem esperança. Segundo Laval (2004, p. XX), a escola neoliberal "permanece ainda como tendência e não uma realidade acabada”. Delinear o novo modelo emergente de escola não significa — diz ele — "que a doutrina liberal seja, desde já, triunfante", pois esse modelo — "quando exposto explicitamente" - é recusado por um número significativo de pessoas "refratárias à nova ideologia" (LAVAL, 2004, p. XX), no mundo inteiro. Lembra que nem todas as dificuldades atuais são por conta das reformas neoliberais, as quais agravam as contradições existentes apesar do discurso da superação. A lógica do empobrecimento dos serviços públicos, a falta de recursos e a penúria dos professores fazem parte da "tradição das elites econômicas e políticas" tanto nos países centrais do capitalismo, como nos nossos do terceiro mundo (LAVAL, 2004, p. XX).

Na visão de Dardot e Laval (2017), no conjunto da vida social, a luta contra o avanço desenfreado do capitalismo, ampliado agora com o neoliberalismo, consiste na busca por formas de vida em comum radicalmente democráticas, pela institucionalização política de outra racionalidade que não a neoliberal, a do capital. No campo da educação escolar, como afirma Laval (2004, p. XXI), a luta contra a escola capitalista e o modelo educacional neoliberal inicia-se com a análise precisa das mutaçóes da escola no novo capitalismo, de sua lógica de conjunto no plano interno, regional, nacional e no âmbito das comparaçôes internacionais. As suas atribuições econômicas, cada vez mais essenciais no modelo neoliberal, devem ser relacionadas "às mutaçôes sociais, políticas e culturais". Da mesma forma, faz-se necessário relacionar as determinaçôes econômicas e sociais externas à dinâmica interna da instituição escolar e "as restriçóes ideológicas às experiências dos indivíduos nas sociedades de mercado em construção" (LAVAL, 2004, p. XXI).

Esse esforço teórico de resistência, para ser eficaz, pressupóe superar um obstáculo inicial - que é a organização institucional da produção do conhecimento, o modelo de reflexão predominante na universidade, que fragmenta o saber, tornando-o insuficiente para apreender a complexidade do social (SAFATLE, 2016). Ainda, acompanhando Laval e concordando com ele, entendemos que o movimento de resistência na escola implica lutar por uma lógica de transformação que negue de maneira radical as atuais reformas contrárias ao princípio da educação pública e instauradoras da lógica mercantil, que impedem a apropriação pelos 
estudantes "de formas simbólicas e dos conhecimentos necessários ao julgamento e ao raciocínio", colocando em seu lugar "aprendizados dóceis às empresas e voltados para a satisfação do interesse privado" (LAVAL, 2004, p. XXI).

Em consonância com o autor, defendemos uma ação transformadora orientada pela defesa da escola pública, universal, comum a todos, capaz de propiciar a toda a população "as condiçôes de assimilação dos conhecimentos indispensáveis a uma vida profissional, mas também muito mais amplamente a uma vida intelectual, estética e social táo rica e variada quanto possível" (LAVAL, 2004, p. XXI). Ideais, como bem recorda Laval (2004), foram gestados pela esquerda, pelos trabalhadores em suas lutas e experiências pedagógicas desde o século XIX, e não podem ser esquecidos. Ideais da escola emancipadora.

É nesse sentido que o Centro de Estudos Educação e Sociedade (CEDES), ao completar 40 anos de luta por uma educação democrática e emancipadora, reafirma seu empenho histórico em defesa da escola pública, laica, gratuita e de qualidade para todos os brasileiros e brasileiras. Pensamos, com isso, reafirmar politicamente os nossos valores e concepçóes, além de honrar a memória de todos aqueles educadores que nos antecederam e que tanto lutaram por um Brasil democrático, mais justo e igualitário.

A comemoração desses anos de luta conjunta com outros sujeitos sociais parceiros na construção da educação democrática, anos marcados por vitórias significativas e também por derrotas pedagógicas, como as que estamos hoje enfrentando, será realizada tanto por meio de iniciativas que propiciem o resgate de nossa memória coletiva, que coincide com a história da educação brasileira, como por meio da organização de espaços de reflexão sobre as contradiçóes e desafios presentes nos cenários nacional e internacional. Além das diferentes ediçóes da Revista Educação e Sociedade, que trarão entrevistas com educadores protagonistas de sua história institucional e a republicação de artigos que constituíram referência teórica nos diferentes períodos de existência do periódico, o CEDES organizará, em 2018, o seu VI Seminário da Educação Brasileira, que terá como tema A educação no atual cenário político-econômico mundial.

A Revista Educação \& Sociedade, produção editorial do CEDES, manifesta seu repúdio à censura expressa na supressão do trabalho "Sistema Nacional de Avaliação da Educação Básica (Sinaeb) - proposta para entender o disposto no Plano Nacional de Educaçáo" para o n. 07 da série PNE em Movimento publicada pelo Instituto Nacional de Estudos e Pesquisas Educacionais Anísio Teixeira (INEP). 
O CEDES e a Revista Educação \& Sociedade prestam homenagens ao seu sócio fundador e colaborador permanente, o querido Celso de Rui Beisiegel, que nos deixou recentemente. Professor da Faculdade de Educaçáo da Universidade de São Paulo (USP), foi defensor intransigente da democratização da escola pública de qualidade. Exímio pesquisador, sua obra é referencial e indispensável à compreensão da história da educação brasileira.

Celso Beisiegel, presente!

\section{Editores da Revista Educaçáo \& Sociedade}

\section{Referências}

BOBBIO, N.; MATTEUCCI; N.; PASQUINO, G. (Orgs.). Dicionário de politica. Brasília: Editora da UnB; São Paulo: Imprensa Oficial, 2000. 2 v.

BONAZZI, T. Conservadorismo. In: BOBBIO, N.; MATTEUCCI; N.; PASQUINO, G. (Orgs.). Dicionário de política. Brasília: Editora da UnB; São Paulo: Imprensa Oficial, 2000. v. 1. p. 242-246.

DARDOT, P.; LAVAL, C. A nova razão do mundo: ensaio sobre a sociedade neoliberal. São Paulo: Boitempo, 2016.

2017.

Comum: ensaio sobre a revolução no século XXI. São Paulo: Boitempo,

LAVAL, C. A escola não é uma empresa: o neo-liberalismo em ataque ao ensino público. Londrina: Planta, 2004.

LOSURDO, D. Liberalismo: entre civilização e barbárie. São Paulo: Anita Garibaldi, 2006.

SAFATLE, V. Gênese da concepção neoliberal de sujeito: Encontros LATESFIP 2016. 2016. Disponível em: <https://www.youtube.com/watch?v=erDxTVZht_g $>$. Acesso em: 1 nov. 2017.

SILVA, A.O. da. O pensamento conservador. Espaço Acadêmico, v. 9, n. 107, p. 53-55, abr. 2010. Disponível em: <http://periodicos.uem.br/ojs/index.php/EspacoAcademico/ article/view/9912/5472>. Acesso em: 19 out. 2017. 